\title{
Atypical Granular Cell Tumour of the Vulva
}

\author{
*Karen Meadley ${ }^{1}$ and Rajalakshmi Rajagopal ${ }^{2}$ \\ ${ }^{1}$ Ayrshire Maternity Unit, NHS Ayrshire and Arran, Scotland \\ ${ }^{2}$ Wishaw General Hospital, NHS Lanarkshire, Scotland
}

Received: October 27,2017; Published: November 02, 2017

*Corresponding author: Karen Meadley, Ayrshire Maternity Unit, NHS Ayrshire and Arran, Scotland, Email: karenmeadley@nhs.net

Keywords: Vulva; Granular cell tumour; Atypical

\section{Background}

Granular cell tumours are benign tumours that are thought to originate from the Schwann cells. They tend to occur in middle aged adults and can be found anywhere in the body in subcutaneous as well as dermis tissue [1]. Most of them are benign with less than $2 \%$ being malignant or atypical. Atypical features are associated with increased morbidity and have a poor prognosis if they become metastatic [2]. They also have a high recurrence rate.

\section{Case Presentation}

A 54-year-old lady was referred by her general practitioner due to a lesion in the left labia majora. Clinical examination revealed a hard, cystic lesion measuring $2 \times 3 \mathrm{~cm}$ on the upper third of the left labia majora which was excised under local anaesthesia and sent for histopathological examination. The diagnosis was atypical granular cell tumour with focal involvement of the peripheral margins. Under general anaesthesia wide excision was performed and the histopathological examination confirmed clear margins. At 5 years follow up there has been no evidence of recurrence.

\section{Discussion}

Granular cell tumours are rare tumours of the skin and subcutaneous tissues. The oral cavity, especially the tongue is the most common site, but the vulva is the most common site in women [2]. Interestingly, the patient we present here had a similar lesion on the tongue in the past which was excised. Unfortunately, the pathology report of that was not available to confirm that this was a granular cell tumour as well. Granular cell tumours usually present as solitary, pale lesions that are slow growing and are relatively painless. The differential diagnosis would be Bartholin's gland tumour, sebaceous cyst, lipoma and papilloma [3]. Histologically, granular cell tumours are found in the dermis and the main morphological feature is the granularity of the cytoplasm, which is caused by massive accumulation of phagolysosomes. Atypical features include prominent nucleoli, high nuclear-to-cytoplasmic ratio, spindling of the tumour cells, necrosis and mitotic activity greater than 2 per 10 high power fields at $200 \mathrm{x}$. If three or more of the features are present, there is the possibility of a malignant granular cell tumour even in the absence of metastasis [4]. Features that make it malignant include: size more than $5 \mathrm{~cm}$, vascular invasion, necrosis, rapid growth, brisk mitotic activity, spindling of cells, angiogenesis and pleomorphism. If less than three of these features are present, the tumour is considered atypical and if none of these features are present, it is classed as benign [5,6].

To the best of our knowledge, ours is the second case to be reported in the English literature. There has only been one case of vulval granular cell tumour with atypical features reported in a preadolescent girl in 2013. A case report presents a 12-year-old girl with a rapidly growing granular cell tumour of the vulva that had atypical features on histology [7].

In our case, histologically, the lesion consisted of nests of round and polyglonal tumour cells with eosinophilic granular cytoplasm, mildly pleomorphic predominantly vesicular nuclei and focally prominent nucleoli. Small lymphoid aggregates and focal lymphoid follicle formation were present. These appearances were in keeping with granular cell tumour. The lesion focally reached peripheral margins and the pathologist felt that there were possibly some suspicious features. A second opinion was sought from a second pathologist and the additional report confirmed that there were atypical features with many of the cells showing vesicular nuclei with prominent nucleoli and nuclear pleomorphism.

\section{Conclusion}

Granular cell tumours are rare, but awareness of their clinical presentation is important since wide local excision is the treatment of choice and is curative if completely excised [8]. After surgical treatment, if there is any evidence of tumour in the surgical margin, wider local excision should be performed. Since $5-25 \%$ of patients 
have multiple lesions, before planning treatment, clinicians should exclude multicentric lesions [9]. The histological findings will determine whether the tumour is benign, atypical or malignant. Patients should be followed up due to the risk of recurrence and since they can be found in any site of subcutaneous tissue or dermis and patients must be aware to report any similar lesions. Recurrence rates are reported as $2-8 \%$ with clear margins and $20 \%$ with positive margins [10].

\section{References}

1. Ashok kumar O, Rodin A (2004) Granular cell tumour of the vulva: very rare neoplasm of female genitalia. Journal of Obstetrics \& Gynaecology 24(7): 830.

2. Cheewakriangkrai C, Sharma S, Deeb G, Lele S (2005) A rare female genital tract tumor: benign granular cell tumor of vulva: case report and review of the literature. Gynecol Oncol 97(2): 656-658.

3. Heller DS (2015) Benign Tumors and Tumor-like Lesions of the Vulva Clin Obstet Gynecol 58(3): 526-535.

4. Kondi-Pafiti A, Kairi-Vassilatou E, Liapis A, Bakalianou K, Iavazzo Ch, et al. (2010) Granular cell tumor of the female genital system. Clinical and pathologic characteristics of five cases and literature review. EurJ Gynaecol Oncol 31(2): 222-224.

5. Ellison JM, Annan HG, Gibbon KL (2003) Granular cell tumour of the vulva: benign infiltrative variety. Journal of Obstetrics \& Gynaecology 23(6): 681.

6. Levavi H, Sabah G, Kaplan B, Tytiun Y, Braslavsky D, et al. (2006) Granular cell tumor of the vulva: six new cases. Archives of Gynecology \& Obstetrics 273(4): 246-249.

7. Kumarapeli AR, Kozielski R (2013) Vulvar atypical granular cell tumor in a preadolescent patient. Journal of Pediatric \& Adolescent Gynecology 26(3): 85-87.

8. Dominguez-Gonzalez M, Nogales-Perez A, Vazquez Navarrete S (2013) Granular cell tumor of the vulva. Journal of Lower Genital Tract Disease 17(1): 82-84.

9. Kardhashi A, Assunta Deliso M, Renna A, Trojano G, Zito FA, et al. (2012) Benign granular cell tumor of the vulva: first report of multiple cases in a family. Gynecologic \& Obstetric Investigation 73(4): 341-348.

10. Rivlin ME, Meeks GR, Ghafar MA, Lewin JR (2013) Vulvar granular cell tumor. World Journal of Clinical Cases: WJCC 1(4): 149-151.

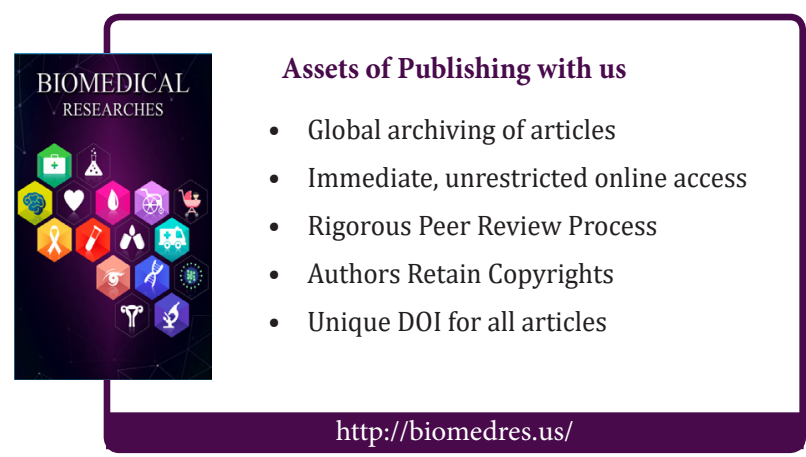

